\title{
ASSESSING CARIES STATUS ACCORDING TO THE CAST INSTRUMENT AND WHO CRITERIA IN 6 - 12 YEARS OLD SCHOOL CHILDREN IN SHIMLA CITY OF HIMACHAL PRADESH
}

\author{
Luxmi Chopra1, Seema Thakur², Parul Singhal', Deepak Chauhan', Cheranjeevi Jayam ${ }^{5}$
}

1Junior Resident, Department of Paediatric and Preventive Dentistry, Himachal Pradesh Government Dental College and Hospital, Shimla, Himachal Pradesh, India.

2Professor and HOD, Department of Paediatric and Preventive Dentistry, Himachal Pradesh Government Dental College and Hospital, Shimla, Himachal Pradesh, India.

${ }^{3}$ Assistant Professor, Department of Paediatric and Preventive Dentistry, Himachal Pradesh Government Dental College and Hospital, Shimla, Himachal Pradesh, India.

${ }^{4}$ Assistant Professor, Department of Paediatric and Preventive Dentistry, Himachal Pradesh Government Dental College and Hospital, Shimla, Himachal Pradesh, India.

${ }^{5}$ Assistant Professor, Department of Paediatric and Preventive Dentistry, Himachal Pradesh Government Dental College and Hospital, Shimla, Himachal Pradesh, India.

\section{BACKGROUND}

\section{ABSTRACT}

Caries Assessment Spectrum and Treatment (CAST) instrument index was introduced for full assessment of dental caries, as it covers from no lesion to advanced stage progression of caries. CAST in comparison to WHO criteria allows a more detailed reporting of stages of dental caries.

Aims and Objectives: To determine the levels of similarity and difference between the CAST instrument and WHO criteria on the basis of caries prevalence, dmft/DMFT counts and reporting of result in $6-12$ years old school children in Shimla city of Himachal Pradesh.

\section{MATERIALS AND METHODS}

A cross-sectional study was carried out among 623 school children aged 6 - 12 years in Shimla city. DMFT (Decayed, Missing, Filled Teeth) counts were obtained according to the WHO criteria and the CAST instrument. Descriptive statistics, test and correlation was done using SPSS version 19. The sample size was taken for convenience during the study.

\section{RESULTS}

623 children were examined. The prevalence of dental caries calculated according to the CAST instrument and the WHO criteria for the primary dentition was $74.47 \%$ and $76.47 \%$ and for the permanent dentition it was $9.93 \%$ and $10.11 \%$.

\section{CONCLUSION}

The CAST instrument provided similar DMF counts as the WHO criteria in all age groups. Presentation of results from use of the CAST instrument in comparison to WHO criteria allowed a more detailed reporting of stages of dental caries, which will be useful for oral health planners.

\section{KEY WORDS}

CAST Instrument, WHO Criteria, Prevalence, Himachal Pradesh.

HOW TO CITE THIS ARTICLE: Chopra L, Thakur S, Singhal P, et al. Assessing caries status according to the CAST instrument and WHO criteria in 6 - 12 years old school children in Shimla city of Himachal Pradesh. J. Evolution Med. Dent. Sci. 2018;7(36):40084011, DOI: $10.14260 /$ jemds/2018/895

\section{BACKGROUND \\ Dental caries is one of the commonest oral diseases in} children affecting $60 \%$ - $90 \%$ of school children. ${ }^{1}$ Despite this fact, not many studies have been done on this issue among school children in Shimla. Children of all age groups are affected by dental caries and its treatment is restorative care, which may even include pulp therapy like indirect pulp capping, pulpotomy and pulpectomy.

'Financial or Other Competing Interest': None.

Submission 15-06-2018, Peer Review 21-08-2018,

Acceptance 27-08-2018, Published 03-09-2018.

Corresponding Author:

Dr. Luxmi Chopra,

Junior Resident,

Department of Paediatric and Preventive Dentistry,

Himachal Pradesh Government Dental College and Hospital,

Shimla, Himachal Pradesh, India.

E-mail: drluxmichopra@gmail.com

DOI: $10.14260 /$ jemds $/ 2018 / 895$

\section{(c) $(1)(5)$}

The lack of availability of dental care, postponement of treatment due to cost considerations and under-utilisation of available facilities not only results in aggravation of the disease, but also enhances the cost of treatment and care. Thus, the best option which is more acceptable and economical for the children is prevention. Therefore, it becomes essential to collect the data on prevalence of dental caries and treatment needs to determine the course of action for preventive care. ${ }^{2}$

The most commonly used indices for recording of dental caries was DMFT index introduced by Klein, Palmer and Knutson (1938) modified by World Health Organization (WHO) in 1987 and 1997.3 However this index did not demonstrate the severity of decay, so the system known as International Caries Detection and Assessment System (ICDAS) and PUFA index were introduced. Components of ICDAS and PUFA index are assembled in CAST (Caries Assessment Spectrum and Treatment) index introduced by Frencken in 2011.4 
CAST index was designed for use in International epidemiological surveys and permits registration of sound teeth, sealants, restorations, enamel and dentine caries lesions, advanced stages of caries lesions into the pulp and tooth-surrounding tissues and teeth lost due to dental caries. The CAST instrument differs from other caries assessment instruments by the fact that the codes are ordered in increasing level of severity of the effects of the caries process. $^{5}$

\section{MATERIALS AND METHODS}

The approval for the study was taken from the ethical committee of Himachal Pradesh Government Dental College and Hospital, Shimla.

The sample frame consisted of junior and middle schools (Public and Government) in Shimla city, and the study sample was recruited by a two-stage cluster sampling technique. A probability sampling method is done for selection of children within each stratum. For the purpose of the study, Shimla city was arbitrarily divided into four zones (North, West, East, South) based on the geographical configuration which corresponded to the four administrative areas of the city: Shimla Municipal and three Shimla Planning Areas (Sanjauli, Chakkar and Kasumpti).

Three schools from Sanjauli, Kasumpti and Shimla Municipal zones where each zone had 9 schools; and 2 schools were from Chakkar that had 7 schools. In the second stage, eligible school children were stratified according to age and gender, and proportions to the total number of 6 to 12 years old students enrolled in each school yielding a sample of 623 pupils.

A total of 623 students ( 345 boys and 278 girls) from these schools were examined over a period of 3 months from June 2017 to September 2017. The sample size was taken for convenience during the study.

\section{Inclusion Criteria}

- Schoolchildren (Male and Female) from 6 to 12 years of age.

- Children present on the day of examination.

\section{Exclusion Criteria}

Students not willing to participate.

Consent was taken from parents or caregivers for the child's participation in the study. In total, 623 children aged between 6 and 12 years were examined during the study. The data concerning the status of primary and permanent teeth in 6 - 12 years old children was obtained by the CAST index and WHO index. The distribution of CAST codes in the examined teeth are correlated with the WHO codes using the Pearson Correlation.

\section{Dental Examination}

One trained and calibrated examiner recorded the dental caries status of each subject using CAST index and WHO criterion. Oral examinations were conducted in school premises. All subjects were examined under adequate light. Before scoring each tooth, it was wiped with a cotton roll to dry the surface. Sterilised instruments including mouth mirror for indirect vision and a probe for removing excess plaque were used for examination. A structured and validated proforma was used to collect and record the data. The proforma included the details of demographic characteristics (name, age and gender) and a dental chart to record data.

If two conditions were present on the same surface, e.g. a filling in one pit and an enamel lesion in another, the higher score was recorded. If an abscess or a fistula was present, it was scored as code 7 . The highest code for each tooth was selected for further analysis.

Examination time was recorded by another examiner using a stop clock, from the moment the other examiner picked up the instruments till he completed the examination. The CAST index was used in the first and WHO criteria was recorded next in the same patient.

\section{Statistical Analysis}

The prevalence of each CAST code and WHO criteria was evaluated for all the primary and the erupted permanent teeth. The dmf/DMF counts obtained through use of the CAST instrument were compared with the WHO criteria by giving code 5 - 7 for decayed teeth, code 8 for the missing teeth and code 2 for the filled teeth.

In the present study, the prevalence of dental caries according to CAST is presented by giving codes 4 - 7 for dentine lesions, codes 3 - 7 for enamel and dentine lesions and codes 2, 5 - 8 for caries experience for comparison with the WHO criterion.

The data was entered in Microsoft Excel sheet and the data analysis was done using statistical software SPSS version 19. Descriptive statistics, Mean DMF scores for comparison between CAST instrument and WHO criteria was calculated. Pearson correlation coefficient ( $\mathrm{r}$ ) was used for analysis. The p-value was setup at 0.05 , which was statistically significant.

\section{RESULTS}

A total of 623 children were examined. Among 623 school children, 345 (55.37\%) were boys and 278 (44.62\%) were girls. Out of 623 school children $156(25.04 \%)$ were 6 years old, $106(17.01 \%)$ were 7 years old, $113(18.13 \%)$ were 8 years old, 96 (15.40) were 9 years old, 60 (9.63\%) were 10 years old, $69(11.07 \%)$ were 11 years old and 23 (3.69\%) were 12 years old.

\begin{tabular}{|c|c|}
\hline Age & N (\%) \\
\hline 6 years & $156(25.04 \%)$ \\
\hline 7 years & $106(17.01 \%)$ \\
\hline 8 years & $113(18.13 \%)$ \\
\hline 9 years & $96(15.40)$ \\
\hline 10 years & $60(9.63 \%)$ \\
\hline 11 years & $69(11.07 \%)$ \\
\hline 12 years & $23(3.69 \%)$ \\
\hline Table 1. Distribution of Study Participants according to \\
Age \\
\hline
\end{tabular}

\begin{tabular}{|c|c|c|c|}
\hline $\begin{array}{c}\text { Cast } \\
\text { Codes }\end{array}$ & Description & Primary Teeth & $\begin{array}{c}\text { Permanent } \\
\text { Teeth }\end{array}$ \\
\hline 0 & Sound & $129(20.70 \%)$ & $489(78.49 \%)$ \\
\hline 1 & Sealed & $0.00 \%$ & $0.00 \%$ \\
\hline 2 & Restored & $21(3.30 \%)$ & $2(0.48 \%)$ \\
\hline 3 & $\begin{array}{c}\text { Distinct visual } \\
\text { changes in enamel }\end{array}$ & $300(48.15 \%)$ & $72(11.55 \%)$ \\
\hline 4 & $\begin{array}{c}\text { Internal caries } \\
\text { related discoloration } \\
\text { in dentin }\end{array}$ & $285(45.74 \%)$ & $17(2.72 \%)$ \\
\hline
\end{tabular}




\begin{tabular}{|c|c|c|c|}
\hline 5 & $\begin{array}{c}\text { Distinct cavitation in } \\
\text { dentin }\end{array}$ & $230(37.00 \%)$ & $19(3.04 \%)$ \\
\hline 6 & $\begin{array}{c}\text { Involvement of pulp } \\
\text { chamber }\end{array}$ & $189(30.33 \%)$ & $23(3.69 \%)$ \\
\hline 7 & Abscess/ Fistula & $12(1.92 \%)$ & $0.00 \%$ \\
\hline 8 & Lost due to caries & $12(1.92 \%)$ & $0.00 \%$ \\
\hline $\begin{array}{c}\text { Table 2. Prevalence Rate of caries in 6- to 12-year-olds } \\
\text { having teeth scored by CAST Codes for the Primary and } \\
\text { Permanent Dentitions }\end{array}$ \\
\multicolumn{4}{|c}{} \\
\multicolumn{4}{|c|}{} \\
\hline
\end{tabular}

\begin{tabular}{|c|c|c|}
\hline WHO Codes & Primary Teeth & Permanent Teeth \\
\hline Sound teeth & $146(23.43 \%)$ & $561(90.04 \%)$ \\
\hline Decayed teeth & $444(71.26 \%)$ & $60(9.63 \%)$ \\
\hline Filled teeth & $21(3.30 \%)$ & $2(0.48 \%)$ \\
\hline Missing teeth & $12(1.92 \%)$ & $(0.00 \%)$ \\
\hline $\begin{array}{c}\text { Table 3. Prevalence Rate of caries in 6- to 12-year-olds } \\
\text { having teeth scored by WHO Codes for the Primary and } \\
\text { Permanent Dentitions }\end{array}$ \\
\hline
\end{tabular}

\begin{tabular}{|c|c|c|c|c|}
\hline Dentition & $\begin{array}{c}\text { Cast } \\
\text { Index }\end{array}$ & $\begin{array}{l}\text { WHO } \\
\text { Index }\end{array}$ & $\begin{array}{c}\text { Significance } \\
\text { Value }\end{array}$ & $\begin{array}{c}\text { Correlation } \\
\text { Coefficient } \\
\text { (r) }\end{array}$ \\
\hline $\begin{array}{c}\text { Dmft count } \\
\text { (Primary } \\
\text { Teeth) }\end{array}$ & $2.07 \%$ & $3.03 \%$ & & $0.95 \%$ \\
\hline $\begin{array}{l}\text { DMFT } \\
\text { (Permanent } \\
\text { Teeth) } \\
\end{array}$ & $0.10 \%$ & $0.13 \%$ & & $0.78 \%$ \\
\hline \multicolumn{5}{|c|}{$\begin{array}{c}\text { Table 4. Mean dmft/DMFT Counts obtained from using } \\
\text { CAST (Codes 2, 5-8) and the WHO Index at 95\% Confidence } \\
\text { Interval }\end{array}$} \\
\hline
\end{tabular}

Similarity in Study Findings between the CAST Instrument and WHO Criterion

Table 4 shows mean dmft and DMFT scores obtained from use of the CAST instrument and WHO criterion. The mean dmft and DMFT scores obtained from using both caries assessment criteria showed no statistically significant difference. The correlation coefficients were all high. The prevalence of dental caries in the primary teeth calculated according to the CAST instrument was $74.47 \%$ and the WHO criteria was $76.47 \%$ and for the permanent dentition it was 9.93\% for CAST instrument and $10.11 \%$ for WHO criteria respectively, showing a high level of agreement.

\section{Differences in Study Findings between CAST Instrument and WHO Criterion}

The prevalence of dental caries (dentine lesions) in primary dentition, calculated according to the CAST instrument and the WHO criteria was $67.73 \%$ and $71.26 \%$, and for the permanent dentition it was $6.73 \%$ and $9.63 \%$ respectively. The proportion of dentine caries lesions assessed as being restorable (codes 4,5 ) was $82.74 \%$ for primary teeth and $5.76 \%$ for permanent teeth. Prevalence of dental caries including enamel and dentine lesions (codes 3 - 7) according to CAST, for the primary and permanent dentition was $75.44 \%$ and $16.53 \%$, respectively. The WHO criteria cannot be used for such a calculation.

\section{DISCUSSION}

A total of 623 students of various schools in Shimla town were included in the present survey. It was found that number of male subjects were comparatively higher as compared to female subjects. In our study, caries was more prevalent in the girls than the boys. This is in agreement with the findings of studies done by Bhardwaj in 2014 in Shimla. ${ }^{6}$

Overall prevalence of dental caries according to CAST for the primary and permanent dentition was $75.44 \%$ and $16.53 \%$, respectively. This was markedly high to a similar studies conducted in Kangra district of Himachal Pradesh, where the prevalence of caries amongst 5 - 12 years old children was found to be $56.8 \% .^{7}$

The mean CAST instrument and WHO criteria time and standard deviations in examining the children were $66.34 \pm$ 3.20 secs and $37.39 \pm 3.59$ secs, respectively $(p=0.26)$.

In this study dentin cavitation was found in $37.00 \%$ of primary teeth and $3.04 \%$ of permanent teeth, pulpal involvement was seen in $30.33 \%$ of primary teeth and $3.69 \%$ of permanent teeth. While $3.30 \%$ of primary teeth and $0.48 \%$ of permanent teeth had been restored. These scores indicate a dental negligence amongst the children and their parents. Such negligence has been seen worldwide in primary teeth. ${ }^{8,9}$

In this study, it was found that the percentage of the participants with decayed, missing and filled teeth had almost similar values when they were evaluated using the DMFT index and CAST index, making the results obtained more easily comparable. The WHO and CAST index scores obtained in the present study did not show any significant difference between dmft/DMFT scores. Thus, for the age group of $6-12$ years, the caries prevalence and caries experience obtained through use of the CAST instrument can be compared with those obtained through using the WHO criterion.

This finding was corroborating with the study conducted by Baginska J and co-workers who studied the status of occlusal surfaces of first permanent molars in 6 to 8-year-old children evaluated by the CAST and DMF indices. ${ }^{10}$ This study showed that mandibular central incisors were least likely to be carious, while the mandibular and maxillary molars were the most affected.

Similarly, the findings were corroborating with the results of studies conducted by Luan et al and Macek et al, who observed that mandibular anterior teeth were least affected. ${ }^{11,12}$

The prevalence of dental caries showed that the most prone tooth for caries were mandibular molars (16.37\%) amongst all the age group and the difference was statistically significant $(\mathrm{p}<0.01)$. The present study reported a high proportion of children having teeth affected with a caries lesion reaching the pulp (30.33\%), which in most cases would require a pulp therapy or an extraction. This study also showed $48.15 \%$ of children with teeth having an enamel caries lesion which would require preventive measures, dental health education and regular surveillance. Therefore, the CAST index is a tool which would enable the health authorities to plan oral health care programs better than the WHO criterion.

\section{CONCLUSION}

The CAST instrument provided similar DMF counts as the WHO criteria in all age groups. Time spent on examining children was less for WHO criteria when compared with CAST instrument. The CAST instrument, in comparison to WHO criteria, allowed a more detailed reporting of stages of dental caries and it is less time consuming and more cost effective which will be useful for oral health planners enabling them to provide better services. The CAST index 
could be a promising tool to be used for epidemiological surveys, as it covers the whole spectrum of caries progression from incipient to advanced carious lesions followed by the treatment status of the tooth.

\section{REFERENCES}

[1] Petersen PE, Bourgeois D, Ogawa H, et al. The global burden of oral diseases and risks to oral health. Bull World Health Organ 2005;83(9):661-9.

[2] Hiremath A, Murugaboopathy V, Ankola AV, et al. Prevalence of dental caries among primary school children of India - a cross-sectional study. Journal of Clinical and Diagnostic Research 2016;10(10):ZC47ZC50.

[3] Klein H, Palmer CE. Studies on dental caries vs. familial resemblance in the caries experience of siblings. Pub Health Rep 1938;53:1353-64.

[4] Frencken JE, de Amorim RG, Faber J, et al. The Caries Assessment Spectrum and Treatment (CAST) index: rational and development. International Dent J 2011;61(3):117-23.

[5] Aeeza M, Malik SS, Ambrina Q, et al. Reliability of cast index for dental caries detection. Medical Forum Monthly 2014;25(04):3-6.

[6] Bhardwaj VK. Dental caries prevalence in individual tooth in primary and permanent dentition among 612-year-old school children in Shimla, Himachal Pradesh. International Journal of Health \& Allied Sciences 2014;3(2):125-8.
[7] Sharma A, Bansal P, Grover A, et al. Oral health status and treatment needs among primary school children in Nagrota Bagwan block of Kangra, Himachal Pradesh. J Indian Society of Periodontics 2014;18(6):762-6.

[8] Mohammadi SN, Prashant GM, Kumar PGN, et al. Dental caries status in 6-14 year old schoolchildren of rural Channagiri, Davangere: a cross - sectional survey. J Indian Assoc Public Health Dent 2015;13(4):389-92.

[9] Saldunaite K, Bendoraitine E, Slabsinskiene E, et al. The role of parental education and socioeconomic status in dental caries prevention among Lithuanian children. Medicina (Kaunas) 2014;50(3):156-61.

[10] Baginska J, Rodakowska E, Milewski R, et al. Dental caries in primary and permanent molars in 7-8-yearold schoolchildren evaluated with Caries Assessment Spectrum and Treatment (CAST) index. BMC Oral Health 2014;14:74.

[11] Luan W, Baelum V, Fejerskov 0, et al. Ten-year incidence of dental caries in adult and elderly Chinese. Caries Res 2000;34(3):205-13.

[12] Macek MD, Beltran-Anguilar ED, Lockwood SA, et al. Updated comparison of the caries susceptibility of various morphological types of permanent teeth. J Public Health Dent 2003;63(3):174-82. 